\title{
Tibial nerve schwanoma: short review of surgical management
}

\section{Guru Dutta Satyarthee ${ }^{1}$, Luis Rafael Moscote-Salazar ${ }^{2}$, Amit Agrawal $^{3}$}

1 Department of Neurosurgery, Neurosciences Centre, AlIMS New

Delhi, INDIA

2 Critical Care Red Latino, Latin American Trauma \& Intensive

Neuro-Care Organization, Bogota, ColomBIA

3 Department of Neurosurgery, All India Institute of Medical

Sciences, Saket Nagar, Madhya Pradesh, India, INDIA

\begin{abstract}
Schwannoma is a benign, solitary nerve sheath tumour and accounting for about $5 \%$ of soft tissue tumours. It can occur along the peripheral nervous system in any part of body. It presents as a painless, swelling. We report an adult male presented with tibial nerve schwanoma underwent successful surgical excision. However, differentiation with neurofibroma is very important as surgical planning and prognosis is quite different. In lower limb usually incidence of neurofibroma is higher in contrast of upper limb. Pertinent literature and management are briefly discussed.
\end{abstract}

\section{INTRODUCTION}

Schwannoma represents a benign peripheral nerve tumour, originating from Schwann cells [1], [2]. It usually presents as a solitary, slow growing mass. It accounting for about $5 \%$ of all soft tissue tumours. lot can present with pain, paraesthesia or rarely with neurological deficit [3], [4], [5].

\section{CASE ILLUSTRATION}

An adult male reported presented with complaints of painless mass with paraesthesia and difficulty in sitting on chair for twoyears. Local examination showed presence of mass in rthe popliteal

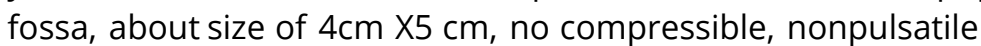
being mobile along transverse axis burt no mobility in craniocaudal axis. A magnetic resonance imaging was carried out to ascertain the nature, revealed presence of a mass lesion causing expansion of tibial nerve. (Fig-1) A provisional diagnosis of peripheral nerve sheath tumour was made and planned for surgical excision. He underwent micro-surgical total excision, intraoperative expansion of the nerve was observed, and nerve fascicles were carefully separated from mass lesion, with electrophysiological nerve monitoring. He had relief in pain and
Keywords

tibial nerve schwannoma,

painless mass, surgery, neuroimaging $\triangle$

Corresponding author: Guru Dutta Satyarthee

Department of Neurosurgery. Neurosciences Centre AlIMS New Delhi, India

duttaguru2002@yahoo.com
Copyright and usage. This is an Open Access article, distributed under the terms of the Creative commons Attribution Non-Commercial No Derivatives License (https://creativecommons .org/licenses/by-nc-nd/4.0/) which permits noncommercial re-use, distribution, and reproduction in any medium, provided the original work is unaltered and is properly cited.

The written permission of the Romanian Society of Neurosurgery must be obtained for commercial re-use or in order to create a derivative work.

ISSN online 2344-4959

(C) Romanian Society of Neurosurgery

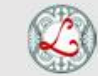

First published March 2019 by London Academic Publishing www.lapub.co.uk 
paraesthesia in post-operative period. Histopathology of resected specimen was suggestive of schwannoma.

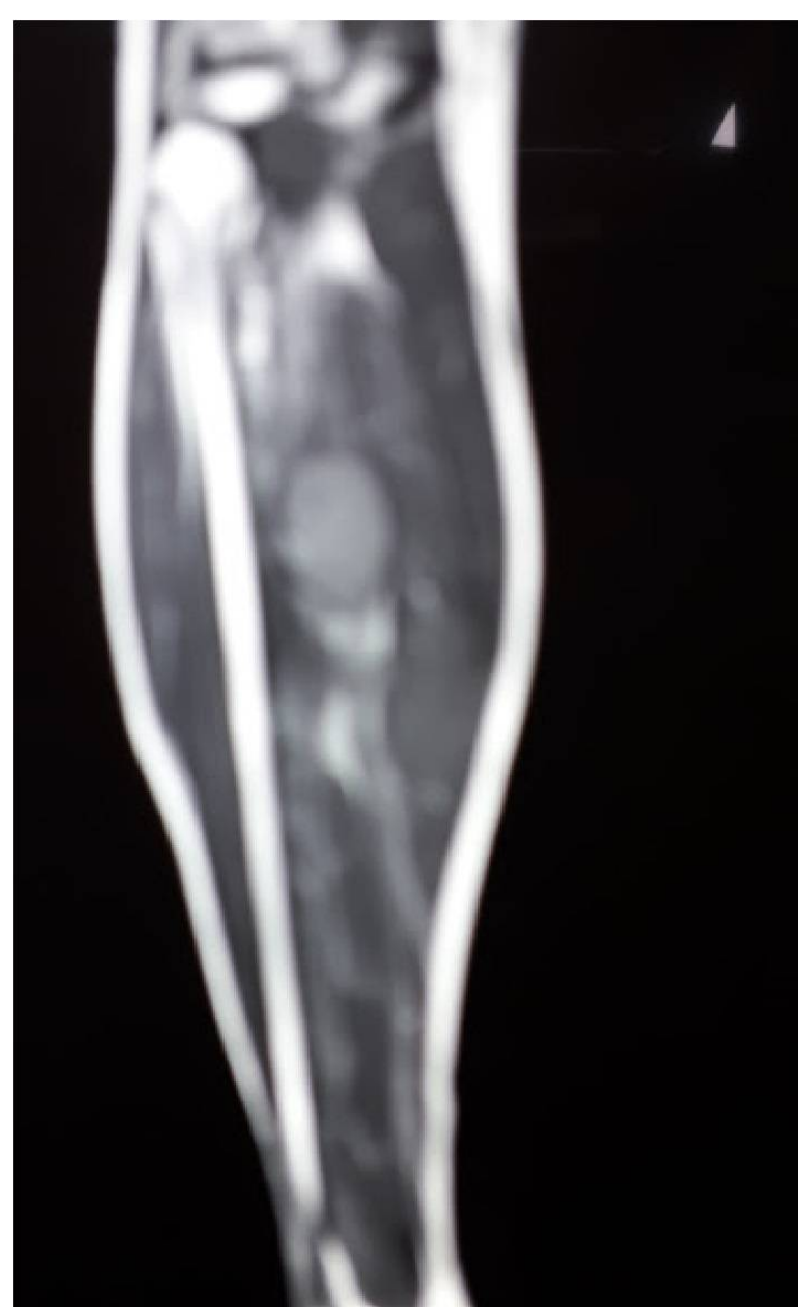

\section{DISCUSSION}

Tibia nerve is continuations of larger terminal branch of the sciatic nerve with root values of L4, L5, S1, S2, and S3 [1], [5], [6], [7] Tibial nerve usually lies superficial to the popliteal vessels, extending from the superior angle to the inferior angle of the popliteal fossa, crossing the popliteal vessels from lateral to medial side [8].

Peripheral nerve sheath schwannoma symptoms are related to alteration in the function of nerve and surrounding muscle and neurovascular bundles, and mostly commonly present with paraesthesia or pain of insidious onset and progresses slowly [2]-[4]. Pain is a much more common symptom than focal motor or sensory deficits. Physical examination may reveal the presence of a mass along the course of the nerve, tender, usually mobile along the transverse axis but limited along the longitudinal course of the nerve, and positive Tinel sign [6], [9].

However, pre-operative confirmatory diagnosis of schwanoma usually not possible in most cases but can help in delineating shape, size, location, extent and relation with parent nerve and adjacent neurovascular structures and muscle. Imaging plays a limited role in distinguishing among various types of peripheral nerve sheath tumours. Magnetic resonance imaging may show presence of fusiform mass with characteristic tapering cephalad and distal ends, fasciculation sign and split fat signs [3], [8], [9]. The mass is well-circumscribed and eccentrically placed, and showing isointense signal on T1weighted images and T2 weighted images shows hyperintense signal and peripheral rim demonstrate hypo-intensity signal representing capsule [3], [5].

After confirmation of diagnosis management of peripheral nerve schwanoma is usually surgical except when the mass is very small and not causing any physical disfigurement.

Treatment of epineurium encapsulated tumour is microsurgical excision with careful preservation of the nerve fascicles. Histopathological examination of specimen provides definitive diagnosis [4], [5]. Kim et al. analysed 397 cases of peripheral nerve sheath tumour, out of which $91 \%$ were benign and the rest were malignant. A total of 251 were located in the brachial plexus region or upper limb. The peripheral nerve sheath tumor involving lower-limbs included 53 cases of neurofibroma and 32 cases of schwannomas [5]. Typically showing the incidence of schwanoma is less than neurofibroma.

Recurrence is uncommon following total surgical excision. Usually surgical excision provides good outcome in view of its benign biological nature and malignant transformation is extremely rare.

\section{CONCLUSION}

Tibial nerve schwanoma is raer entity compared to neurofibroma and prognosis and surgical planning should be discussed and prognosticated to patient as imaging may also may not definitely distinguish between neurofibroma, schwanoma. However electrophysiological monitoring is an important aid in preserving neurological outcome. Hence, every surgical team member should be always considering the possibility of neurofibroma, schwanoma. 


\section{REFERENCES}

1. Maleux G, Byrs P, Samson I, Sciot R, Baert AL: Giant schwannoma of the lower leg. Eur Radiol 1997; 7:10311034.

2. Arnold CA, Kastrup JJ, Rogers VP: Neurilemoma about the knee: a case report. Am J Sports Med 1999; 27:668-670.

3. Blanchard C, Dam-Hieu P, Zagnoli F, Bellard S: [Chronic sciatic pain caused by sciatic nerve schwannoma]. Rev Med Interne. 2008; 29 (9): 748-50.

4. Munakomi S, Shrestha P: Case Report: Sciatic nerve schwannoma - a rare cause of sciatica. F1000Research. 2017; 6 .

5. Kim DH, Murovic JA, Tiel RL, Moes G, Kline DG: A series of 397 peripheral neural sheath tumors: 30-year experience at Louisiana State University Health Sciences Center. J Neurosurg. 2005; 102 (2): 246-55.
6. Wasa J, Nishida $Y$, Tsukushi $S$, Shido $Y$, Sugiura $H$, Nakashima $\mathrm{H}$, Ishiguro $\mathrm{N}$ : MRI features in the differentiation of malignant peripheral nerve sheath tumors and neurofibromas.AJR AmJ Roentgenol. 2010; 194 (6): 1568-74.

7. Schreuder HW, Veth RP, Pruszczynski M, Lemmens JA,van Laarhoven EW: Intraosseous schwannoma (neurilemoma) of the cervical spine. Sarcoma 2001; 5:101-103.

8. Kehoe NJ, Reid RP, Semple JC: Solitary benign peripheral nerve tumors: review of 32 years' experience. J Bone Joint Surg Br 1995; 77:497-500.

9. Byun JH, Hong JT, Son BC, Lee SW: Schwannoma of the superficial peroneal nerve presenting as sciatica. J Korean Neurosurg Soc 2005; 38:306-308. 